\title{
Convergence theorems and stability results of pointwise asymptotically nonexpansive mapping in Banach space
}

\author{
Qiansheng Feng ${ }^{\mathrm{a}, *}$, Nan Jiang ${ }^{\mathrm{a}}$, Yongfu Su ${ }^{\mathrm{b}}$ \\ ${ }^{a}$ Department of Mathematics, Tianjin University, Tianjin, 300354, China. \\ ${ }^{b}$ Department of Mathematics, Tianjin Polytechnic University, Tianjin, 300387, China. \\ Communicated by N. Shahzad
}

\begin{abstract}
The purpose of this paper is to approximate the fixed point of pointwise asymptotically nonexpansive mapping using the generalized Mann and generalized Ishikawa iterative scheme. And under the condition that the pointwise asymptotically nonexpansive mapping is compact, the stability results of the two iterative schemes are studied. The main results of this paper modify and improve many important recent results in the literature. (C)2017 All rights reserved.
\end{abstract}

Keywords: Pointwise asymptotically nonexpansive mapping, generalized Mann iterative scheme, generalized Ishikawa iterative scheme, stability result, convergence theorem.

2010 MSC: 47H05, 47H09, 47H10.

\section{Introduction}

Many nonlinear problems are closely related to the nonlinear operator equations, and the solutions of the nonlinear operator equations can often be transformed into fixed points of some nonlinear operators. Therefore, the fixed point theory of nonlinear operator is a basic tool of nonlinear science. In recent years, many iterations and approximations of fixed points of nonlinear operators have been widely studied.

In 2008, Kirk and $\mathrm{Xu}$ [10] first introduced the definition of pointwise asymptotically nonexpansive mapping (see Definition 2.1). And they proved that the pointwise asymptotically nonexpansive mapping has a fixed point in a bounded uniformly convex Banach space. Moreover, the set of fixed points is closed convex. In 2011, Balooee [2] proved weak and strong convergence theorems of the pointwise asymptotically nonexpansive mapping in Hilbert space using the generalized Ishikawa iterative scheme and the monotone hybrid method, respectively. Later, Kozlowoski [11] proved that the sequence generated by the generalized Mann (and the generalized Ishikawa) iterative scheme converges weakly to a fixed point of the pointwise asymptotically nonexpansive mapping in a bounded uniformly convex Banach space with Opial's property. In addition, he also proved strong convergence theorems under the condition

\footnotetext{
${ }^{*}$ Corresponding author

Email addresses: fengqiansheng-2008@163.com (Qiansheng Feng), nanj@tju.edu.cn (Nan Jiang), suyongfu@tjpu.edu.cn (Yongfu Su)
}

doi:10.22436/jnsa.010.10.04 
that the pointwise asymptotically nonexpansive mapping is compact. In 2013, Khalilzadeh and Sarikhani [7] proved that the sequence generated by the generalized Mann iterative scheme converges weakly to a fixed point of the pointwise asymptotically nonexpansive mapping in a bounded uniformly convex Banach space with Fréchet differentiable norm.

However, Balooee obtained his main results under the strong condition that the pointwise asymptotically nonexpansive mapping is uniformly L-Lipschitian in Hilbert space. Kozlowoski and Khalilzadeh proved their main theorems in the Banach space, but the proof of Kozlowoski's result is based on the condition that $\gamma_{n}(x)$ is a bounded function for every $n \geqslant 1$. And in the proof of Khalilzadeh, he did not prove the crucial result of $\lim _{n \rightarrow \infty}\left\|T x_{n}-x_{n}\right\|=0$ that was used in his proof. In this paper, we first prove that the sequences generated by the generalized Mann and the generalized Ishikawa iterative scheme converge weakly to a fixed point of the pointwise asymptotically nonexpansive mapping in a uniformly convex Banach space with the Opial's property. Then based on the condition that pointwise asymptotically nonexpansive mapping is a compact mapping, we prove that the generalized Mann and the generalized Ishikawa iterative scheme are stable in a uniformly convex Banach space with the Opial's property. The highlight of this paper is a new demiclosedness principle which makes us not use the result that $\lim _{n \rightarrow \infty}\left\|T x_{n}-x_{n}\right\|=0$ in the process of proving the main theorem. Of course, we do not need to use the condition that $\gamma_{\mathfrak{n}}(x)$ being a bounded function. Recent demiclosedness principles can be found in $[4,12,18]$.

\section{Preliminaries}

Definition 2.1. Let $X$ be a Banach space, and $C$ be a bounded, closed, and convex subset of $X$. A mapping $\mathrm{T}: \mathrm{X} \rightarrow \mathrm{X}$ is said to be pointwise asymptotically nonexpansive if

$$
\left\|T^{n} x-T^{n} y\right\| \leqslant \gamma_{n}(x)\|x-y\|, \quad \forall x, y \in C, \quad n \in N,
$$

where $\left\{\gamma_{n}(x)\right\}$ is a sequence in $[0,+\infty)$ and $\gamma_{n} \rightarrow 1$ pointwise on $C$.

In formula (2.1), if $\left\{\gamma_{n}\right\}$ is the sequence independent of $x$, then the mapping $T$ is a asymptotically nonexpansive [5]. It is obvious that an asymptotically nonexpansive mapping is pointwise asymptotically nonexpansive, reverse is not true. There are many questions about the pointwise asymptotically nonexpansive mapping in practical applications. Here we give an example of pointwise asymptotically nonexpansive mapping as follows.

Example 2.2. Let $C$ be a nonempty closed subset of the complex set $\mathfrak{R}$. Let $f$ be a continuously differentiable self-mapping of $C$. For two systems $x_{n+1}=f\left(x_{n}\right)$ and $y_{n+1}=f\left(y_{n}\right)$ with initial point $x_{0}$ and $y_{0}$, respectively, if the initial error $\left|x_{0}-y_{0}\right|$ is sufficiently small, then there exists $x_{0}^{1} \in\left[x_{0}, y_{0}\right]$ such that

$$
\left|x_{1}-y_{1}\right|=\left|f\left(x_{0}\right)-f\left(y_{0}\right)\right|=\left|f^{\prime}\left(x_{0}^{1}\right)\right|\left|x_{0}-y_{0}\right|,
$$

where $f^{\prime}(x)$ represents the first derivative of $f(x)$. Similarly, there exists $x_{1}^{1} \in\left[x_{1}, y_{1}\right]$ such that

$$
\left|x_{2}-y_{2}\right|=\left|f\left(x_{1}\right)-f\left(y_{1}\right)\right|=\left|f^{\prime}\left(x_{1}^{1}\right)\right|\left|f^{\prime}\left(x_{0}^{1}\right)\right|\left|x_{0}-y_{0}\right|,
$$

and

$$
\left|x_{n}-y_{n}\right|=\left|f\left(x_{n-1}\right)-f\left(y_{n-1}\right)\right|=\prod_{k=0}^{n-1}\left|f^{\prime}\left(x_{k}^{1}\right)\right|\left|x_{0}-y_{0}\right|, \quad x_{k}^{1} \in\left[x_{k}, y_{k}\right] .
$$

It can be seen that $x_{0}^{1}$ is related to the initial value $x_{0}$ and $x_{k}^{1}$ is related to $x_{k}$. In addition, $\left\{x_{k}\right\}$ is the sequence generated by the mapping $f$ and the initial value $x_{0}$. Thus $x_{k}^{1}$ is related to the initial value $x_{0}$.

The sensitivity of the two systems to the initial perturbation is determined by the value of the derivative $f^{\prime}(x)$ at the initial value $x_{0}$. The overall sensitivity of the mapping to the initial value requires performing the iterations for $n$ times and averaging all the "initial conditions". 
Let $\gamma_{\mathrm{n}}\left(x_{0}\right)=\prod_{k=0}^{n-1}\left|f^{\prime}\left(x_{k}^{1}\right)\right|$, we have $\gamma_{n}\left(x_{0}\right) \geqslant 0$ and

$$
\left|x_{n+1}-y_{n+1}\right|=\left|f\left(x_{n}\right)-f\left(y_{n}\right)\right| \leqslant \gamma_{n+1}\left(x_{0}\right)\left|x_{0}-y_{0}\right| .
$$

Assume $C \triangleq[-1-i, 1+i]$ and $f(x)=e^{i x}$, then $\lim _{n \rightarrow \infty} \gamma_{n}\left(x_{0}\right)=\lim _{n \rightarrow \infty} \prod_{k=0}^{n-1}\left|i e^{i x_{k}}\right|=1$, then $f$ is a pointwise asymptotically nonexpansive mapping.

Remark 2.3. It is not hard to see that $f$ is not asymptotically nonexpansive mapping if function $f^{\prime}(x)$ is not a constant.

In Definition 2.1, we said that the mapping $T$ is pointwise asymptotically contraction if $\gamma_{n}(x) \leqslant 1$ and $\lim _{n \rightarrow \infty} \gamma_{n}(x)=\gamma \in[0,1)$. The fixed point theorem for pointwise asymptotically contraction mappings and its applications have been studied by Kirk [8, 9], Xu [19], and Arandjelvić [1]. So here we just consider the case of $\theta_{\mathfrak{n}}(x)=\max \left\{\gamma_{\mathfrak{n}}(x), 1\right\}$. Denote $\Gamma(C)$ as the class of pointwise asymptotically nonexpansive mapping T satisfying $\lim _{n \rightarrow \infty} \theta_{\mathfrak{n}}(x)=1$. Define $b_{\mathfrak{n}}(x)=\theta_{\mathfrak{n}}(x)-1$, it is clear that $\lim _{n \rightarrow \infty} b_{n}(x)=0$.

Definition 2.4. Define $\Gamma_{\mathrm{r}}(\mathrm{C})$ as a class of all $\mathrm{T} \in \Gamma(\mathrm{C})$ such that

$$
\sum_{n=1}^{\infty} b_{n}(x)<\infty, \quad \forall x \in C .
$$

Definition 2.5. A sequence $\left\{t_{n}\right\} \subset(0,1)$ is called bounded away from 0 if there exists $0<a<1$ such that $t_{n}>a$ for every $n \in N$. Similarly, $\left\{t_{n}\right\} \subset(0,1)$ is called bounded away from 1 if there exists $0<b<1$ such that $t_{n}<b$ for every $n \in N$.

Lemma 2.6 ([16]). Let $X$ be a uniformly convex Banach space. Let $\left\{t_{n}\right\} \subset(0,1)$ be bounded away from 0 and 1 , and $\left\{u_{n}\right\},\left\{v_{n}\right\} \subset X$ be such that

$$
\limsup _{n \rightarrow \infty}\left\|u_{n}\right\| \leqslant a, \quad \limsup _{n \rightarrow \infty}\left\|v_{n}\right\| \leqslant a, \quad \lim _{n \rightarrow \infty}\left\|t_{n} u_{n}+\left(1-t_{n}\right) v_{n}\right\|=a .
$$

Then $\lim _{n \rightarrow \infty}\left\|u_{n}-v_{n}\right\|=0$.

Lemma 2.7 ([17]). Let $\left\{s_{n}\right\}$ and $\left\{h_{n}\right\}$ be two sequences of nonnegative real numbers satisfying the following inequality

$$
s_{\mathrm{n}+1} \leqslant\left(1+\delta_{\mathrm{n}}\right) \mathrm{s}_{\mathrm{n}}+\mathrm{h}_{\mathrm{n}}, \quad \forall \mathrm{n} \in \mathrm{N},
$$

where $\delta_{n} \in(0,1)$. If $\sum_{n=1}^{\infty} \delta_{n}<\infty$ and $\sum_{n=1}^{\infty} h_{n}<\infty$, then $\lim _{n \rightarrow \infty} s_{n}$ exists.

Definition 2.8 ([13]). A Banach space $X$ is said to satisfy Opial's condition if $\left\{x_{n}\right\}$ is a sequence in $X$ which converges weakly to $x \in X$, then

$$
\limsup _{n \rightarrow \infty}\left\|x_{n}-x\right\|<\limsup _{n \rightarrow \infty}\left\|x_{n}-y\right\|, \quad \forall y \in X, y \neq x .
$$

Lemma 2.9 ([10]). Assume $X$ is a uniformly convex Banach space and $C$ is a bounded closed convex subset of X. Then every pointwise asymptotically nonexpansive mapping $\mathrm{T}: \mathrm{C} \rightarrow \mathrm{C}$ has a fixed point. Moreover, the set of fixed points of $\mathrm{T}$ is closed convex.

In this paper, we use $F(T)$ to denote the set of all fixed points of the mapping $T$.

Lemma 2.10 (Demiclosedness principle). Let C be a nonempty closed convex sunset of a uniformly convex Banach space $\mathrm{X}$ which satisfies Opial's condition and let $\mathrm{T} \subset \Gamma_{\mathrm{r}}(\mathrm{C})$. Then $\mathrm{I}-\mathrm{T}$ is demiclosed at zero, that is, if $\left\{\mathrm{x}_{\mathrm{n}}\right\}$ is a sequence in $C$ such that $x_{n} \rightarrow q$ and $\lim _{m \rightarrow \infty} \limsup _{n \rightarrow \infty}\left\|x_{n}-T^{m} x_{n}\right\|=0$, then $(I-T) q=0$.

Proof.

(1) If $\mathrm{T}^{\mathrm{m}} \mathrm{q}=\mathrm{q}$ for each $\mathrm{m} \in \mathrm{N}$, taking $\mathrm{m}=1$ we have $\mathrm{Tq}=\mathrm{q}$. 
(2) If there exists an $N_{0}>0$ and for each $m \geqslant N_{0}$, such that $T^{m} q \neq q$, we can define a function $f$ on $X$ by

$$
f(x)=\limsup _{n \rightarrow \infty}\left\|x_{n}-x\right\|, \quad x \in E .
$$

From $x_{n} \rightarrow q$ and (2.2), we have that

$$
f(q)=\limsup _{n \rightarrow \infty}\left\|x_{n}-q\right\|<\underset{n \rightarrow \infty}{\limsup }\left\|x_{n}-T^{m} q\right\|=f\left(T^{m} q\right) .
$$

On the other hand

$$
\begin{aligned}
f\left(T^{m} q\right)=\limsup _{n \rightarrow \infty}\left\|x_{n}-T^{m} q\right\| & =\limsup _{n \rightarrow \infty}\left\|x_{n}-T^{m} x_{n}+T^{m} x_{n}-T^{m} q\right\| \\
& \leqslant \limsup _{n \rightarrow \infty}\left(\left\|x_{n}-T^{m} x_{n}\right\|+\left\|T^{m} x_{n}-T^{m} q\right\|\right) \\
& \leqslant \limsup _{n \rightarrow \infty}\left\|x_{n}-T^{m} x_{n}\right\|+\limsup _{n \rightarrow \infty} \theta_{m}(q)\left\|x_{n}-q\right\| .
\end{aligned}
$$

So we have the following inequality

$$
\limsup _{n \rightarrow \infty}\left\|x_{n}-T^{m} q\right\| \leqslant \limsup _{n \rightarrow \infty}\left\|x_{n}-T^{m} x_{n}\right\|+\theta_{m}(q) \limsup _{n \rightarrow \infty}\left\|x_{n}-q\right\| .
$$

Since $\lim _{m \rightarrow \infty} \theta_{m}(x)=1$ for each $x \in C$ and $\lim _{m \rightarrow \infty} \limsup _{n \rightarrow \infty}\left\|x_{n}-T^{m} x_{n}\right\|=0$, so for all $\varepsilon>0$, there exists $N_{1} \in N$, when $m>N_{1}$, we have that

$$
\theta_{\mathrm{m}}(x)<1+\varepsilon, \quad \forall x \in C
$$

and

$$
\limsup _{n \rightarrow \infty}\left\|x_{n}-T^{m} x_{n}\right\|<\varepsilon
$$

From (2.4), (2.5), and (2.6), we get that

$$
\limsup _{n \rightarrow \infty}\left\|x_{n}-T^{m} q\right\| \leqslant \varepsilon+(1+\varepsilon) \limsup _{n \rightarrow \infty}\left\|x_{n}-q\right\| .
$$

By the arbitrariness of $\varepsilon$ and (2.7), we have

$$
\limsup _{n \rightarrow \infty}\left\|x_{n}-T^{m} q\right\| \leqslant \limsup _{n \rightarrow \infty}\left\|x_{n}-q\right\| .
$$

Taking $\mathrm{N}_{2}=\max \left\{\mathrm{N}_{0}, \mathrm{~N}_{1}\right\}$ and $\mathrm{m}>\mathrm{N}_{2}$, by (2.8) and (2.3) we derive that

$$
\limsup _{n \rightarrow \infty}\left\|x_{n}-T^{m} q\right\| \leqslant \limsup _{n \rightarrow \infty}\left\|x_{n}-q\right\|<\limsup _{n \rightarrow \infty}\left\|x_{n}-T^{m} q\right\|,
$$

which is a contradiction. So we have $T^{m} q=q$ for any $m \in N$, hence $T q=q$.

\section{Weak convergence theorem}

In this section, we prove that the sequences generated by the generalized Mann and the generalized Ishikawa iterative scheme converge weakly to a fixed point of a pointwise asymptotically nonexpansive mapping in a Banach space.

Theorem 3.1. Let $\mathrm{X}$ be a uniformly convex Banach space which satisfies Opial's condition, and $\mathrm{C}$ be a nonempty closed convex subset of $\mathrm{X}$. Let $\mathrm{T} \in \Gamma_{\mathrm{r}}(\mathrm{C})$, and $\left\{\mathrm{x}_{\mathrm{n}}\right\}$ be the sequence generated by the generalized Mann iterative scheme as follows

$$
\left\{\begin{array}{l}
x_{1} \in C, \text { arbitrarily, } \\
x_{n+1}=\alpha_{n} x_{n}+\left(1-\alpha_{n}\right) T^{n} x_{n},
\end{array}\right.
$$

where $\left\{\alpha_{n}\right\} \subset(0,1)$ is a sequence bounded away from 1 and 0 . Then $\left\{x_{n}\right\}$ converges weakly to a fixed point of $\mathrm{T}$. 
Proof. First we prove that $\left\{x_{n}\right\}$ is bounded and $\lim _{n \rightarrow \infty}\left\|x_{n}-p\right\|$ exists for each $p \in F(T)$. In fact, from (3.1) and T being a pointwise asymptotically nonexpansive mapping, we have that

$$
\begin{aligned}
\left\|x_{n+1}-p\right\| & =\left\|\alpha_{n}\left(x_{n}-p\right)+\left(1-\alpha_{n}\right)\left(T^{n} x_{n}-p\right)\right\| \\
& \leqslant \alpha_{n}\left\|x_{n}-p\right\|+\left(1-\alpha_{n}\right)\left\|T^{n} x_{n}-p\right\| \\
& \leqslant\left[\alpha_{n}+\left(1-\alpha_{n}\right) \theta_{n}(p)\right]\left\|x_{n}-p\right\| \\
& \leqslant\left[1+b_{n}(p)\right]\left\|x_{n}-p\right\| .
\end{aligned}
$$

Since $\sum_{n=1}^{\infty} b_{n}(p)<\infty$, together with Lemma 2.7 we get that $\lim _{n \rightarrow \infty}\left\|x_{n}-p\right\|$ exists. This implies that $\left\{x_{n}\right\}$ is bounded.

Next we prove that $\lim _{n \rightarrow \infty}\left\|x_{n}-T^{n} x_{n}\right\|=0$. By above description there exists a real number such that $\lim _{n \rightarrow \infty}\left\|x_{n}-p\right\|=a$. Hence

$$
\lim _{n \rightarrow \infty}\left\|T^{n} x_{n}-p\right\|=\lim _{n \rightarrow \infty}\left\|T^{n} x_{n}-T^{n} p\right\| \leqslant \lim _{n \rightarrow \infty} \theta_{n}(p)\left\|x_{n}-p\right\|=a
$$

and

$$
\lim _{n \rightarrow \infty}\left\|\alpha_{n}\left(x_{n}-p\right)+\left(1-\alpha_{n}\right)\left(T^{n} x_{n}-p\right)\right\|=\lim _{n \rightarrow \infty}\left\|x_{n+1}-p\right\|=a .
$$

By Lemma 2.6, we get that

$$
\lim _{n \rightarrow \infty}\left\|x_{n}-T^{n} x_{n}\right\|=0 .
$$

Since the sequence $\left\{x_{n}\right\}$ is bounded so there exists a subsequence $\left\{x_{n_{k}}\right\}$ of $\left\{x_{n}\right\}$ such that $x_{n_{k}} \rightarrow q$ for some $q \in C$. By $\lim _{n \rightarrow \infty}\left\|x_{n}-T^{n} x_{n}\right\|=0$ and Lemma 2.10, we get that $q \in F(T)$.

Next we prove that $\left\{x_{n}\right\}$ converges weakly to q. Take another subsequence $\left\{x_{m_{k}}\right\}$ of $\left\{x_{n}\right\}$ such that $x_{m_{k}} \rightarrow p$ for some $p \in C$. Again, as above, we conclude that $p \in F(T)$. Now we show that $q=p$ by reduction to absurdity. We assume that $q \neq p$, since $\lim _{n \rightarrow \infty}\left\|x_{n}-u\right\|$ exists for every $u \in F(T)$ and since $q, p \in F(T)$, by (2.2), we have that

$$
\lim _{n \rightarrow \infty}\left\|x_{n}-q\right\|=\lim _{k \rightarrow \infty}\left\|x_{n_{k}}-q\right\|<\lim _{k \rightarrow \infty}\left\|x_{n_{k}}-p\right\|=\lim _{k \rightarrow \infty}\left\|x_{m_{k}}-p\right\|<\lim _{k \rightarrow \infty}\left\|x_{m_{k}}-q\right\|=\lim _{n \rightarrow \infty}\left\|x_{n}-q\right\| .
$$

This means $\lim _{n \rightarrow \infty}\left\|x_{n}-q\right\|<\lim _{n \rightarrow \infty}\left\|x_{n}-q\right\|$, which is a contradiction. So we get that $q=p$.

Theorem 3.2. Let $X$ be a uniformly convex Banach space which satisfies Opial's condition, and $\mathrm{C}$ be a nonempty closed convex subset of $\mathrm{X}$. Let $\mathrm{T} \in \Gamma_{\mathrm{r}}(\mathrm{C})$, and $\left\{\mathrm{x}_{\mathrm{n}}\right\}$ be the sequence generated by the generalized Ishikawa iterative scheme as follows

$$
\left\{\begin{array}{l}
x_{1} \in C, \text { arbitrarily, } \\
z_{n}=\beta_{n} x_{n}+\left(1-\beta_{n}\right) T^{n} x_{n}, \\
x_{n+1}=\alpha_{n} x_{n}+\left(1-\alpha_{n}\right) T^{n} z_{n},
\end{array}\right.
$$

where $\left\{\alpha_{n}\right\},\left\{\beta_{n}\right\} \subset(0,1)$ are sequences bounded away from 1 and 0 . Then $\left\{x_{n}\right\}$ converges weakly to a fixed point of $\mathrm{T}$.

Proof. First we prove that $\left\{x_{n}\right\}$ is bounded and $\lim _{n \rightarrow \infty}\left\|x_{n}-p\right\|$ exists for each $p \in F(T)$. In fact, from (3.2) and $T \in \Gamma_{r}(C)$, we have that

$$
\begin{aligned}
\left\|x_{n+1}-p\right\| & =\left\|\alpha_{n}\left(x_{n}-p\right)+\left(1-\alpha_{n}\right)\left(T^{n} z_{n}-p\right)\right\| \\
& \leqslant \alpha_{n}\left\|x_{n}-p\right\|+\left(1-\alpha_{n}\right)\left\|T^{n} z_{n}-p\right\| \\
& \leqslant \alpha_{n}\left\|x_{n}-p\right\|+\left(1-\alpha_{n}\right) \theta_{n}(p)\left\|z_{n}-p\right\|
\end{aligned}
$$

and

$$
\begin{aligned}
\left\|z_{n}-p\right\| & =\left\|\beta_{n}\left(x_{n}-p\right)+\left(1-\beta_{n}\right)\left(T^{n} x_{n}-p\right)\right\| \\
& \leqslant \beta_{n}\left\|x_{n}-p\right\|+\left(1-\beta_{n}\right)\left\|T^{n} x_{n}-p\right\| \\
& \leqslant \beta_{n}\left\|x_{n}-p\right\|+\left(1-\beta_{n}\right) \theta_{n}(p)\left\|x_{n}-p\right\| \\
& \leqslant \theta_{n}(p)\left\|x_{n}-p\right\| .
\end{aligned}
$$


Substituting (3.4) in (3.3) yields

$$
\begin{aligned}
\left\|x_{n+1}-p\right\| & \leqslant \alpha_{n}\left\|x_{n}-p\right\|+\left(1-\alpha_{n}\right) \theta_{n}^{2}(p)\left\|x_{n}-p\right\| \\
& =\left[1+\left(1-\alpha_{n}\right)\left(\theta_{n}^{2}(p)-1\right)\right]\left\|x_{n}-p\right\| \leqslant\left[1+\left(\theta_{n}^{2}(p)-1\right)\right]\left\|x_{n}-p\right\| .
\end{aligned}
$$

Since $\theta_{n}^{2}(p)-1=b_{n}^{2}(p)+2 b_{n}(p)$ and $\sum_{n=1}^{\infty} b_{n}(p)<\infty$, then $\sum_{n=1}^{\infty}\left(\theta_{n}^{2}(p)-1\right)<\infty$. It follows from (3.5) and Lemma 2.7 that $\lim _{n \rightarrow \infty}\left\|x_{n}-p\right\|$ exists. This implies that $\left\{x_{n}\right\}$ is bounded.

Next we prove that $\lim _{n \rightarrow \infty}\left\|x_{n}-T^{n} x_{n}\right\|=0$. By above description there exists a real number such that $\lim _{n \rightarrow \infty}\left\|x_{n}-p\right\|=a$. From (3.3) we can conclude that

$$
\lim _{n \rightarrow \infty}\left\|x_{n+1}-p\right\| \leqslant \lim _{n \rightarrow \infty} \alpha_{n}\left\|x_{n}-p\right\|+\lim _{n \rightarrow \infty}\left(1-\alpha_{n}\right) \theta_{n}(p)\left\|z_{n}-p\right\| .
$$

This together with $\lim _{n \rightarrow \infty} \theta_{n}(p)=1$ and the fact that $\left\{\alpha_{n}\right\}$ is bounded away from 0 and 1 , we get that

$$
\lim _{n \rightarrow \infty}\left\|z_{n}-p\right\| \geqslant a \text {. }
$$

On the other hand, form (3.4) we can conclude that

$$
\lim _{n \rightarrow \infty}\left\|z_{n}-p\right\| \leqslant a .
$$

From (3.6) and (3.7), it is clear that

$$
\lim _{n \rightarrow \infty}\left\|z_{n}-p\right\|=a
$$

Since

and from (3.8),

$$
\lim _{n \rightarrow \infty}\left\|T^{n} x_{n}-p\right\|=\lim _{n \rightarrow \infty}\left\|T^{n} x_{n}-T^{n} p\right\| \leqslant \lim _{n \rightarrow \infty} \theta_{n}(p)\left\|x_{n}-p\right\|=a
$$

$$
\lim _{n \rightarrow \infty}\left\|\beta_{n}\left(x_{n}-p\right)+\left(1-\beta_{n}\right)\left(T^{n} x_{n}-p\right)\right\|=\lim _{n \rightarrow \infty}\left\|z_{n}-p\right\|=a .
$$

By Lemma 2.6, we get that

$$
\lim _{n \rightarrow \infty}\left\|x_{n}-T^{n} x_{n}\right\|=0 .
$$

Since the sequence $\left\{x_{n}\right\}$ is bounded so there exists a subsequence $\left\{x_{n_{k}}\right\}$ of $\left\{x_{n}\right\}$ such that $x_{n_{k}} \rightarrow q$ for some $q \in$ C. By (3.9) and Lemma 2.10, we get that $q \in F(T)$.

Next we prove that $\left\{x_{n}\right\}$ converges weakly to q. Take another subsequence $\left\{x_{m_{k}}\right\}$ of $\left\{x_{n}\right\}$ such that $x_{m_{k}} \rightarrow p$ for some $p \in C$. Again, as above, we conclude that $p \in F(T)$. Now we show that $q=p$ by reduction to absurdity. We assume that $q \neq p$, since $\lim _{n \rightarrow \infty}\left\|x_{n}-u\right\|$ exists for every $u \in F(T)$ and since $q, p \in F(T)$, by (2.2), we have that

$$
\lim _{n \rightarrow \infty}\left\|x_{n}-q\right\|=\lim _{k \rightarrow \infty}\left\|x_{n_{k}}-q\right\|<\lim _{k \rightarrow \infty}\left\|x_{n_{k}}-p\right\|=\lim _{k \rightarrow \infty}\left\|x_{m_{k}}-p\right\|<\lim _{k \rightarrow \infty}\left\|x_{m_{k}}-q\right\|=\lim _{n \rightarrow \infty}\left\|x_{n}-q\right\| .
$$

This means $\lim _{n \rightarrow \infty}\left\|x_{n}-q\right\|<\lim _{n \rightarrow \infty}\left\|x_{n}-q\right\|$, which is a contradiction. So we get that $q=p$.

\section{Stability results}

Stability results of various iterative processes for fixed points of many nonlinear operators were established in metric space, normed linear space, and Banach space $[3,6,14,15,20,21]$. In this section, we discuss the stability results of the generalized Mann and the generalized Ishikawa iterative scheme for fixed point of pointwise asymptotically nonexpansive mapping in a uniformly convex Banach space.

Let $X$ be a Banach space, $T$ be a self-mapping of $X$, and $x_{n+1}=g\left(T, x_{n}\right)$ be an iterative scheme. Suppose that $T$ has at least one fixed point and that sequence $\left\{x_{n}\right\}$ converges strongly to $x \in F(T)$. Let $\left\{y_{n}\right\} \subset X$ be an arbitrary sequence and $\varepsilon_{n}=\left\|y_{n+1}-g\left(T, y_{n}\right)\right\|$.

If $\lim _{n \rightarrow \infty} \varepsilon_{n}=0$ implies that $\lim _{n \rightarrow \infty} y_{n}=x$, then the iterative scheme $x_{n+1}=g\left(T, x_{n}\right)$ is said to be T-stable. stable.

If $\sum_{n=1}^{\infty} \varepsilon_{n}<\infty$ implies that $\lim _{n \rightarrow \infty} y_{n}=x$, then we say that the iterative scheme $x_{n+1}=g\left(T, x_{n}\right)$ is 
Theorem 4.1. Let $\mathrm{X}$ be a uniformly convex Banach space which satisfies Opial's condition, and $\mathrm{C}$ be a nonempty closed convex subset of $\mathrm{X}$. Let $\mathrm{T} \in \Gamma_{\mathrm{r}}(\mathrm{C})$ and $\mathrm{T}^{\mathrm{n}}$ be a compact mapping. Let $\mathrm{gM}\left(\mathrm{T}, \mathrm{x}_{\mathrm{n}}\right)$ be the generalized Mann iterative scheme (3.1), and $\left\{\alpha_{n}\right\} \subset(0,1)$ is a sequence bounded away from 1 and 0 . Then the iterative scheme $\mathrm{gM}\left(\mathrm{T}, \mathrm{x}_{\mathrm{n}}\right)$ is stable.

Proof. Let $\left\{y_{n}\right\}$ be an arbitrary sequence such that $\sum_{n=1}^{\infty} \varepsilon_{n}<\infty$. For each $p \in F(T)$, since $T$ is a pointwise asymptotically nonexpansive mapping, we have that

$$
\left\|y_{n+1}-p\right\| \leqslant \varepsilon_{n}+\left\|g M\left(T, y_{n}\right)-p\right\| \leqslant \varepsilon_{n}+\left[1+b_{n}(p)\right]\left\|y_{n}-p\right\| .
$$

Since $\sum_{n=1}^{\infty} b_{n}(p)<\infty$ and $\sum_{n=1}^{\infty} \varepsilon_{n}<\infty$, so together with Lemma 2.7 we get that $\left\{y_{n}\right\}$ is bounded and there exists a real number a such that

$$
\lim _{n \rightarrow \infty}\left\|y_{n}-p\right\|=a
$$

On the other hand,

$$
\lim _{n \rightarrow}\left\|T^{n} y_{n}-p\right\| \leqslant \lim _{n \rightarrow} \theta_{n}(p)\left\|y_{n}-p\right\| \leqslant a,
$$

and from (4.1)

$$
\lim _{n \rightarrow \infty}\left\|\alpha_{n}\left(y_{n}-p\right)+\left(1-\alpha_{n}\right)\left(T^{n} y_{n}-p\right)\right\|=\lim _{n \rightarrow \infty}\left\|g M\left(T, y_{n}\right)-p\right\|=a .
$$

By Lemma 2.6, we conclude that

$$
\lim _{n \rightarrow \infty}\left\|y_{n}-T^{n} y_{n}\right\|=0 .
$$

Because of $T^{n}$ being a compact mapping, so there exits a subsequence $\left\{y_{n_{k}}\right\}$ of $\left\{y_{n}\right\}$ and a $q \in X$ such that

$$
\lim _{k \rightarrow \infty}\left\|T^{n_{k}} y_{n_{k}}-q\right\|=0
$$

And from formula (4.2),

$$
\lim _{k \rightarrow \infty}\left\|y_{n_{k}}-q\right\| \leqslant \lim _{k \rightarrow \infty}\left\|y_{n_{k}}-T^{n_{k}} y_{n_{k}}\right\|+\lim _{k \rightarrow \infty}\left\|T^{n_{k}} y_{n_{k}}-q\right\|=0
$$

By Lemma 2.10, we can obtain that $q \in F(T)$. Since $\lim _{n \rightarrow \infty}\left\|y_{n}-q\right\|=a$, thus $\lim _{n \rightarrow \infty} y_{n}=q$.

Theorem 4.2. Let $\mathrm{X}$ be a uniformly convex Banach space which satisfies Opial's condition, and $\mathrm{C}$ be a nonempty closed convex subset of $\mathrm{X}$. Let $\mathrm{T} \in \Gamma_{\mathrm{r}}(\mathrm{C})$ and $\mathrm{T}^{\mathrm{n}}$ be a compact mapping. Let $\mathrm{gI}\left(\mathrm{T}, \mathrm{x}_{\mathrm{n}}\right)$ be the generalized Ishikawa iterative scheme (3.2), and $\left\{\alpha_{n}\right\},\left\{\beta_{n}\right\} \subset(0,1)$ be sequences bounded away from 1 and 0 . Then the iterative scheme $\mathrm{gI}\left(\mathrm{T}, \mathrm{x}_{\mathrm{n}}\right)$ is stable.

Proof. Let $\left\{y_{n}\right\}$ be an arbitrary sequence such that $\sum_{n=1}^{\infty} \varepsilon_{n}<\infty$. For each $p \in F(T)$, it follows that

$$
\left\|y_{n+1}-p\right\| \leqslant \varepsilon_{n}+\left\|g I\left(T, y_{n}\right)-p\right\| .
$$

By the definition of $g I\left(T, x_{n}\right)$ and pointwise asymptotically nonexpansiveness of $T$, we have that

$$
\begin{aligned}
\left\|g I\left(T, y_{n}\right)-p\right\| & =\left\|\alpha_{n}\left(y_{n}-p\right)+\left(1-\alpha_{n}\right)\left(T^{n} z_{n}-p\right)\right\| \\
& \leqslant \alpha_{n}\left\|y_{n}-p\right\|+\left(1-\alpha_{n}\right)\left\|T^{n} z_{n}-p\right\| \\
& \leqslant \alpha_{n}\left\|y_{n}-p\right\|+\left(1-\alpha_{n}\right) \theta_{n}(p)\left\|z_{n}-p\right\|
\end{aligned}
$$

and

$$
\begin{aligned}
\left\|z_{n}-p\right\| & =\left\|\beta_{n}\left(y_{n}-p\right)+\left(1-\beta_{n}\right)\left(T^{n} y_{n}-p\right)\right\| \\
& \leqslant \beta_{n}\left\|y_{n}-p\right\|+\left(1-\beta_{n}\right)\left\|T^{n} y_{n}-p\right\| \\
& \leqslant \beta_{n}\left\|y_{n}-p\right\|+\left(1-\beta_{n}\right) \theta_{n}(p)\left\|y_{n}-p\right\| \\
& \leqslant \theta_{n}(p)\left\|y_{n}-p\right\| .
\end{aligned}
$$


Substituting (4.4) and (4.5) in (4.3) yields

$$
\left\|y_{n+1}-p\right\| \leqslant \varepsilon_{n}+\left[1+\left(\theta_{n}(p)^{2}-1\right)\right]\left\|y_{n}-p\right\| \leqslant \varepsilon_{n}+\left[1+\left(b_{n}(p)^{2}+2 b_{n}(p)\right)\right]\left\|y_{n}-p\right\| .
$$

Since $\sum_{n=1}^{\infty} b_{n}(p)<\infty$ and $\sum_{n=1}^{\infty} \varepsilon_{n}<\infty$, so by Lemma 2.7 we get that $\left\{y_{n}\right\}$ is bounded and there exists a real number a such that

$$
\lim _{n \rightarrow \infty}\left\|y_{n}-p\right\|=a .
$$

From (4.5) and $\lim _{\mathfrak{n} \rightarrow \infty} \theta_{\mathfrak{n}}(p)=1$ we have

$$
\lim _{n \rightarrow \infty}\left\|z_{n}-p\right\| \leqslant a .
$$

Actually $\lim _{n \rightarrow \infty}\left\|z_{n}-p\right\|=a$. If $\lim _{n \rightarrow \infty}\left\|z_{n}-p\right\|<a$, then from (4.4)

$$
\lim _{n \rightarrow \infty}\left\|g I\left(T, y_{n}\right)-p\right\|<a \text {. }
$$

This together with (4.3) implies that

$$
a=\lim _{n \rightarrow \infty}\left\|y_{n+1}-p\right\| \leqslant \lim _{n \rightarrow \infty} \varepsilon_{n}+\lim _{n \rightarrow \infty}\left\|g I\left(T, y_{n}\right)-p\right\|<a,
$$

which is a contradiction, so

$$
\lim _{n \rightarrow \infty}\left\|z_{n}-p\right\|=a
$$

Since

and from (4.6)

$$
\lim _{n \rightarrow}\left\|T^{n} y_{n}-p\right\| \leqslant \lim _{n \rightarrow} \theta_{n}(p)\left\|y_{n}-p\right\| \leqslant a,
$$

$$
\lim _{n \rightarrow \infty}\left\|\beta_{n}\left(y_{n}-p\right)+\left(1-\beta_{n}\right)\left(T^{n} y_{n}-p\right)\right\|=\lim _{n \rightarrow \infty}\left\|z_{n}-p\right\|=a .
$$

By Lemma 2.6, we get that

$$
\lim _{n \rightarrow \infty}\left\|y_{n}-T^{n} y_{n}\right\|=0 .
$$

Since $T^{n}$ is a compact mapping, so there exits a subsequence $\left\{y_{n_{k}}\right\}$ of $\left\{y_{n}\right\}$ and a $q \in X$ such that

$$
\lim _{k \rightarrow \infty}\left\|\mathrm{T}^{n_{k}} y_{n_{k}}-q\right\|=0
$$

And from formula (4.7)

$$
\lim _{k \rightarrow \infty}\left\|y_{n_{k}}-q\right\| \leqslant \lim _{k \rightarrow \infty}\left\|y_{n_{k}}-T^{n_{k}} y_{n_{k}}\right\|+\lim _{k \rightarrow \infty}\left\|T^{n_{k}} y_{n_{k}}-q\right\|=0 .
$$

By Lemma 2.10, we can obtain that $q \in F(T)$. Since $\lim _{n \rightarrow \infty}\left\|y_{n}-q\right\|=a$, thus $\lim _{n \rightarrow \infty} y_{n}=q$.

\section{Acknowledgment}

This work has been supported by the National Natural Science Foundation of China (Grant No. 11332006, 1127223311572221), National key basic research and development program (plan 973) (NO. 2012CB720101NO. 2012CB720103).

\section{References}

[1] I. D. Arandjelović, Note on asymptotic contractions, Appl. Anal. Discrete Math., 1 (2007), 211-216. 2

[2] J. Balooee, Weak and strong convergence theorems of modified Ishikawa iteration for an infinitely countable family of pointwise asymptotically nonexpansive mappings in Hilbert spaces, Arab J. Math. Sci., 17 (2011), 153-169. 1

[3] A. O. Bosede, B. E. Rhoades, Stability of Picard and Mann iteration for a general class of functions, J. Adv. Math. Stud., 3 (2010), 23-25.4 
[4] H. Dehghan, Demiclosed principle and convergence of a hybrid algorithm for multivalued *-nonexpansive mappings, Fixed Point Theory, 14 (2013), 107-115. 1

[5] K. Goebel, W. A. Kirk, A fixed point theorem for asymptotically nonexpansive mappings, Proc. Amer. Math. Soc., 35 (1972), 171-174. 2

[6] A. M. Harder, T. L. Hicks, Stability results for fixed point iteration procedures, Math. Japon., 33 (1988), 693-706. 4

[7] G. Khalilzadeh, R. Sarikhani, Fixed Point for pointwise asymptotically nonexpansive mapping in Banach Space which has Frechet Differential Norm, Int. J. Math. Anal., 7 (2013), 425-432. 1

[8] W. A. Kirk, Fixed points of asymptotic contractions, J. Math. Anal. Appl., 277 (2003), 645-650. 2

[9] W. A. Kirk, Asymptotic pointwise contractions, Plenary Lecture, the 8th International Conference on Fixed Point Theory and Its Applications, Chiang Mai University, Thailand, (2007), 16-22. 2

[10] W. A. Kirk, H.-K. Xu, Asymptotic pointwise contractions, Nonlinear Anal., 69 (2008), 4706-4712. 1, 2.9

[11] W. M. Kozlowski, Fixed point iteration processes for asymptotic pointwise nonexpansive mappings in Banach spaces, J. Math. Anal. Appl., 377 (2011), 43-52. 1

[12] Z. Ma, L. Wang, Demiclosed principle and convergence theorems for asymptotically strictly pseudononspreading mappings and mixed equilibrium problems, Fixed Point Theory Appl., 2014 (2014), 20 pages. 1

[13] Z. Opial, Weak convergence of the sequence of successive approximations for nonexpansive mappings, Bull. Amer. Math. Soc., 73 (1967), 591-597. 2.8

[14] S. Rezapour, R. H. Haghi, B. E. Rhoades, Some results about T-stability and almost T-stability, Fixed Point Theory, 12 (2011), 179-186. 4

[15] B. E. Rhoades, Fixed point theorems and stability results for fixed point iteration procedures, Indian J. Pure Appl. Math., 21 (1990), 1-9. 4

[16] J. Schu, Weak and strong convergence to fixed points of asymptotically nonexpansive mappings, Bull. Austral. Math. Soc., 43 (1991), 153-159. 2.6

[17] K.-K. Tan, H. K. Xu, Approximating fixed points of nonexpansive mappings by the Ishikawa iteration process, J. Math. Anal. Appl., 178 (1993), 301-308. 2.7

[18] R. Wangkeeree, H. Dehghan, Strong and-convergence of Moudafi's iterative scheme in CAT(0) spaces, J. Nonlinear Conv. Anal., 16 (2015), 299-309. 1

[19] H.-K. Xu, Asymptotic and weakly asymptotic contractions, Indian J. Pure Appl. Math., 36 (2005), 145-150. 2

[20] Q. Yuan, B. E. Rhoades, T-Stability of Picard Iteration in Metric Spaces, Fixed Point Theory and Appl., 2008 (2008), 4 pages. 4

[21] T. Zamfirescu, Fix point theorems in metric spaces, Arch. Math., 23 (1972), 292-298. 4 